University of Windsor

Scholarship at UWindsor

6-5-2009

\title{
The influence of shyness on the use of Facebook in an undergraduate sample
}

\author{
Emily S. Orr \\ Mia Sisic \\ University of Windsor \\ Craig Ross \\ Mary G. Simmering \\ Jaime M. Arseneault
}

See next page for additional authors

Follow this and additional works at: https://scholar.uwindsor.ca/psychologypub

Part of the Psychology Commons

\section{Recommended Citation}

Orr, Emily S.; Sisic, Mia; Ross, Craig; Simmering, Mary G.; Arseneault, Jaime M.; and Orr, Robert. (2009). The influence of shyness on the use of Facebook in an undergraduate sample. CyberPsychology \& Behavior, 12 (3), 340-337.

https://scholar.uwindsor.ca/psychologypub/32

This Article is brought to you for free and open access by the Department of Psychology at Scholarship at UWindsor. It has been accepted for inclusion in Psychology Publications by an authorized administrator of Scholarship at UWindsor. For more information, please contact scholarship@uwindsor.ca. 


\section{Authors}

Emily S. Orr, Mia Sisic, Craig Ross, Mary G. Simmering, Jaime M. Arseneault, and Robert Orr 


\title{
Rapid Communication
}

\section{The Influence of Shyness on the Use of Facebook in an Undergraduate Sample}

\author{
Emily S. Orr, M.A., Mia Sisic, B.A., Craig Ross, M.A., Mary G. Simmering, M.A., \\ Jaime M. Arseneault, M.A., and R. Robert Orr, Ph.D.
}

\begin{abstract}
Researchers have suggested that individual differences will help to determine which online communication tools appeal to and are used by different individuals. With respect to the domain of computer-mediated communication, shyness is a particular personality trait of interest, as forums provide opportunities for social interactions that shy individuals might otherwise avoid. The present study investigated the personality trait of shyness and its relation with certain features of an online communication tool (Facebook). We hypothesized that shyness would be significantly related to the quantity of time spent on Facebook, the number of contacts added to one's Facebook profile, and attitudes toward Facebook. Our findings supported that shyness was significantly positively correlated with the time spent on Facebook and having favorable attitudes toward the social networking site. Furthermore, shyness was significantly negatively correlated with the number of Facebook "Friends." Limitations of the present study and suggestions for future research are addressed.
\end{abstract}

\section{Introduction}

T HE INTERNET HAS BEEN a part of our lives for almost two decades, and online communication (e.g., e-mail, instant messaging, chat rooms, and social networking sites) continues to evolve in an attempt to appeal to the general public. One potential benefit of computer-mediated communication (CMC) is the possibility of expanding one's social network. This particular feature of Internet use may be more appealing to those who have difficulty engaging in social communication in the real world, such as those who are shy. Consequently, the purpose of this investigation was to determine whether shyness was related to the use of a social networking site.

McKenna and Bargh ${ }^{1}$ proposed that variables associated with online communication, such as anonymity, the bridging of physical distance, perceived control of conversations, and overcoming the barrier of physical attractiveness, can be appealing to CMC users. Moreover, they asserted that these various features, in conjunction with individual and personality differences, will determine one's pattern of Internet use. In this context, McKenna and Bargh suggested that social researchers would be best advised to focus their efforts on individual differences (e.g., shyness) that might explain the use of online communication tools.
Among the variety of online tools now available for communication, social networking sites are one of the newest, and they provide a rich source of potential research for social scientists. Social networking sites (SNSs) are online Web sites that allow individuals to create personal profiles visible to others using the site in an attempt to establish or increase an online social network. Examples of SNSs include Facebook, MySpace, Lava Life, and Plenty of Fish, all of which serve the purpose of connecting individuals with other users of the same site.

\section{Shyness in online forums}

Shyness is characterized by anxiety reactions (e.g., tension, discomfort, aversion of gaze) and an inhibition of normal social behaviors when in the presence of others. ${ }^{2}$ This pattern of inhibition may also be evident in online interactions. Madell and Muncer ${ }^{3}$ reviewed the use of Internet communication tools by shy individuals. In particular, they reviewed usage patterns of e-mail, chat rooms, and instant messaging. They found that shyness was negatively correlated with e-mail usage but unrelated to use of chat rooms or instant messaging. Madell and Muncer explained the negative association between shyness and e-mail usage by proposing that shy individuals did not have sufficient social 
contacts with whom to exchange e-mail. They concluded that shyness did not encourage greater use of online communication tools, but also that it did not act as a barrier.

Conversely, Sheeks and Birchmeier ${ }^{4}$ argued that the desire to find gratifying social relationships for shy individuals may result in a greater reliance on online communication tools. In their investigation of the perceived advantages of CMC tools for shy individuals, they found that shy individuals were more likely than nonshy individuals to report satisfying relationships established online. Similarly, Ward and Tracey ${ }^{5}$ found that shy individuals were more likely to establish online relationships. However, shy participants still expressed greater difficulty in their online relationships, relative to nonshy participants.

The results of these studies tend to support the notion that shyness is not a barrier to online interaction and may facilitate engagement in online relationships (e.g., online dating ${ }^{8}$ ). Given the anonymity that can be afforded to individuals in online forums, it is not surprising that shy individuals might be more willing to engage in online interactions than offline interactions, given their discomfort in social situations. Thus, Sheeks and Birchmeier argued that "because of the perceived control features of CMC, people with social inhibitions (i.e., the socially anxious or shy) often turn to the Internet to meet their social and intimacy needs." $4(\mathrm{p} 65)$

\section{The present study}

The purpose of this study was to establish whether shyness was related to the use of Facebook. Given that shy individuals typically report having fewer friends than do nonshy individuals in the offline world, ${ }^{6}$ we hypothesized that shy individuals would also have fewer Facebook "Friends." Moreover, given the anonymity afforded to individuals in online interactions, we hypothesized that shyness would be positively correlated with time spent on Facebook. Furthermore, we hypothesized that shy individuals would have more favorable attitudes toward Facebook, as online communication tools have previously been shown to meet the social needs of shy individuals. ${ }^{4}$

\section{Method}

\section{Participants}

One hundred three undergraduate students at a university in southwestern Ontario enrolled in the present study. The sample included 16 men and 87 women, and the mean age was 21.50 years $(S D=5.29)$, with a range of 17 to 52 years. Of this range, $94 \%$ of the participants were 27 years old or younger. Students were compensated with partial course credit for their participation.

\section{Materials}

Online questionnaires were used to evaluate participants' self-reported shyness, use of Facebook (including time spent on Facebook and the number of Facebook Friends), attitudes toward Facebook, and the relations among these variables. Participants were asked to indicate how many minutes they spent on Facebook on a daily basis using a 6-point Likert scale ranging from 1, 10 or less, to 6, 3+ hours. They were also asked to indicate how many Facebook Friends they had on their profile in an open-ended format.

Six items from Ellison et al. ${ }^{7}$ and an additional item composed by the authors ("How satisfied are you with Facebook overall?") were utilized to investigate attitudes toward Facebook. The maximum possible score of the 7-item composite was 35 (indicating very favorable attitudes toward Facebook). There was a minimum possible score of 0 (indicating very unfavorable attitudes toward Facebook). Cronbach's alpha was 0.84 for all the items in the present study.

Shyness was measured via the Revised Cheek and Buss Shyness Scale (RCBS-20). ${ }^{8}$ There are several versions of this scale, which vary in the number of items contained in the questionnaire. The version used in the present study consisted of 20 items rated on a 5-point Likert scale. Scores can range from a minimum of 20 (very nonshy) to a high of 100 (very shy). This version of the RCBS-20 has demonstrated good reliability, ${ }^{9,10}$ and both this scale and alternate forms of the CBS have been shown to have adequate psychometric properties. ${ }^{11,12}$ The RCBS-20 was demonstrated to be reliable in the present study $(\alpha=0.88)$.

\section{Procedure}

Participants were recruited through the university's psychology participation pool. After indicating an interest in the study, participants were sent an e-mail containing the study's URL as well as the necessary login credentials. Although the survey was hosted on the university's Web server, it was not possible to access the study Web site without these credentials. Participants were also provided with an individual identification code that allowed them to return to their survey if they were accidentally disconnected. The data presented here were part of a larger battery focused on correlates of CMC use. The total battery took approximately 60 minutes to complete. Participants were recruited over a 2-week timeframe in February 2008.

Table 1. Correlation Matrix

\begin{tabular}{lcccc}
\hline & Shyness & Time & Friends & Attitudes \\
\hline Shyness & 1.00 & $0.24^{*}$ & $-0.25^{*}$ & $0.28^{*}$ \\
Time $^{\mathrm{a}}$ & & 1.00 & $0.27^{*}$ & $0.60^{* *}$ \\
Friends $^{\mathrm{b}}$ & & & 1.00 & 0.12 \\
Attitudes $^{\mathrm{c}}$ & & & 1.00 \\
\hline
\end{tabular}

${ }^{\text {aTime }}=$ How many minutes per day do you spend on Facebook?

${ }^{\mathrm{b}}$ Friends = Approximately how many friends are on your Facebook Friends list?

${ }^{\mathrm{c}}$ Attitudes $=$ Composite of attitudes toward Facebook derived from Ellison et al. ${ }^{7}$ and an additional item added by the authors.

${ }^{* *} p<0.01$ (two-tailed); ${ }^{*} p<0.05$ (two-tailed). 


\section{Results}

A mean shyness score of $52.55(S D=14.17)$ was found with this sample. There was no significant difference between men and women with respect to shyness, $t(98)=$ $-0.241, p>0.05$. Age, however, was significantly correlated with shyness, $r(97)=-0.334, p<0.01$. Given that shyness demonstrates both situational and temporal stability ${ }^{13}$ and that the majority (94\%) of the sample was 27 years of age or younger, age was not controlled for in further analyses.

Our sample had an average of 224 Facebook Friends added to their profiles $(S D=143)$. With respect to the amount of time spent on Facebook, a mean score of $2.33(S D=1.21)$ was obtained using the 6-point Likert scale described previously, indicating that participants reported spending just over 30 minutes daily on Facebook. Finally, participants recorded a mean of $22.06(S D=5.78)$ on the attitudes toward Facebook composite.

A correlation matrix was created to explore the associations among shyness, time spent on Facebook, number of Facebook Friends, and attitudes toward Facebook, see Table 1. As predicted, shyness was significantly positively correlated with the amount of time spent on Facebook. In other words, shy individuals reported spending more time on Facebook, supporting our first hypothesis. Consistent with our second hypothesis, shyness was significantly negatively associated with the number of Facebook Friends. That is, as participants' self-reported levels of shyness increased, they reported having fewer Facebook contacts on their profile.

In terms of the relation between shyness and attitudes toward Facebook, correlational analysis revealed that shyness was significantly positively correlated with attitudes toward Facebook. Consistent with our final hypothesis, shy individuals were more likely to have favorable attitudes toward Facebook.

\section{Discussion}

The results of this study indicate that the dispositional trait of shyness is significantly related to features of Facebook use as well as to attitudes held toward this form of CMC. Specifically, we found that shyness significantly predicted the number of Friends added to one's Facebook profile. This suggests that shy individuals have fewer friends in this online forum, relative to nonshy individuals. These results are commensurate with offline trends indicating that shy individuals have fewer reported friendships. ${ }^{6}$ Additionally, we found that shy individuals reported spending more time on Facebook. Finally, we found that attitudes toward Facebook were significantly associated with shyness, such that shy individuals reported having more favorable attitudes toward Facebook than did nonshy individuals. These findings all served to support our hypotheses.

Together, these findings suggest that although shy individuals do not have as many contacts on their Facebook profiles, they still regard this tool as an appealing method of communication and spend more time on Facebook than do nonshy individuals. Such findings might be explained by the anonymity afforded by online communication, specifically, the removal of many of the verbal and nonverbal cues associated with face-to-face interactions. As Ward and Tracey 8 suggested, this anonymity may appeal to shy individuals, and therefore they appreciate the medium despite not using it to its full potential (i.e., adding more Facebook Friends). Moreover, as suggested by Sheeks and Birchmeier, ${ }^{4}$ the characteristics associated with shyness may result in a reliance of shy individuals on online communication tools. Therefore, it is not surprising that our results revealed a significant positive correlation between time spent on Facebook and shyness.

A particular limitation of the present study is the generalizability of the sample. While Facebook was originally developed with the intent of linking individuals on a college campus, ${ }^{7}$ it is now open to all individuals, regardless of whether they have academic affiliation. Therefore, it is possible that the findings of the present study, using only a sample of university students, will not generalize to other Facebook users who do not attend university or college. Another limitation of the present study was the method with which time spent on Facebook was assessed. Participants were limited to a 6-point Likert scale to report the quantity of time they spent on this site. Had this item been recorded in an open-ended format, it is possible that a stronger, more representative correlation would have been obtained.

Accordingly, future researchers in this domain would be well served to investigate the time spent on Facebook through open-ended questions for continuous variables such as time. Moreover, it is possible that shyness is significantly related to different facets of Facebook that are specific to this online communication tool, such as posting photos with personal content and messaging others in a public forum. Therefore, future researchers may choose to explore these Facebook-specific functions and the association between these functions and personality traits such as shyness. Finally, future researchers might also consider replicating these results with a nonuniversity sample in order to ascertain whether these findings hold for the entire Facebook population.

\section{Disclosure Statement}

The authors have no conflict of interest.

\section{References}

1. McKenna KYA, Bargh JA. Plan 9 from cyberspace: the implications of the Internet for personality and social psychology. Personality and Social Psychology Review 2000; 4:57-75.

2. Buss AH. (1980) Self-consciousness and social anxiety. San Francisco: Freeman.

3. Madell D, Muncer S. Internet communication: an activity that appeals to shy and socially phobic people? CyberPsychology \& Behavior 2006; 9:618-22.

4. Sheeks MS, Birchmeier ZP. Shyness, sociability, and the use of computer-mediated communication in relationship development. CyberPsychology \& Behavior 2007; 10:64-70.

5. Ward CG, Tracey TJG. Relation of shyness with aspects of online relationship involvement. Journal of Social \& Personal Relationships 2004; 21:611-23.

6. Jones WH, Carpenter BN. (1986) Shyness, social behavior, and relationships. In Jones WH, Cheeks JM, \& Briggs SR, eds. Shyness: perspectives on research and treatment. New York: Plenum Press, pp. 227-39.

7. Ellison NB, Steinfield C, Lampe C. The benefits of Facebook "friends": social capital and college students' use of online 
social network sites. Journal of Computer-Mediated Communication 2007; 12:1143-68.

8. Cheek JM, Melchior LA. (1985) Measuring the three components of shyness. In Davis MH, Franzoi SL (cochairs), Emotion, personality, and personal well-being II. Symposium conducted at the annual convention of the American Psychological Association, Los Angeles. www.wellesley.edu/Psychology/Cheek/ research.html\#20item (accessed July 18, 2008).

9. Cheek JM, Krasnoperova EN. (1990) Varieties of shyness in adolescence and adulthood. In Schmidt LA, Schulkin J, eds. Extreme fear, shyness, and social phobia. New York: Plenum Press, pp. 47-84.

10. Melchior LA, Cheek JM. Shyness and anxious self-preoccupation during a social interaction. Journal of Social Behavior \& Personality 1990; 5:117-30.

11. Cheek JM, Briggs SR. (1990) Shyness as a personality trait. In Crozier WR, ed. Shyness and embarrassment: perspectives from social psychology. Cambridge: Cambridge University Press, pp. 315-37.
12. Bruch MA. (2001) Shyness and social interaction. In Crozier WR, Alden LE, eds. International handbook of social anxiety. Chichester: Wiley, pp.187-94.

13. Briggs SR. (1985) A trait account of social shyness. In Shaver $\mathrm{P}$, ed. Review of personality and social psychology, Vol. 6. Beverly Hills: Sage.

Address reprint requests to: Emily S. Orr Department of Psychology University of Windsor

173 Chrysler Hall South 401 Sunset Avenue Windsor, Ontario Canada N9B 3P4

E-mail: orre@uwindsor.ca 
Copyright of CyberPsychology \& Behavior is the property of Mary Ann Liebert. Inc. and its content may not be copied or emailed to multiple sites or posted to a listserv without the copyright holder's express written permission. However, users may print, download, or email articles for individual use. 